\title{
Conventional pap's test and liquid-based cytology for the screening of cervical cancer with back up colposcopy directed biopsy
}

\author{
Sabera Khatun and Sayada Fatema Khatun
}

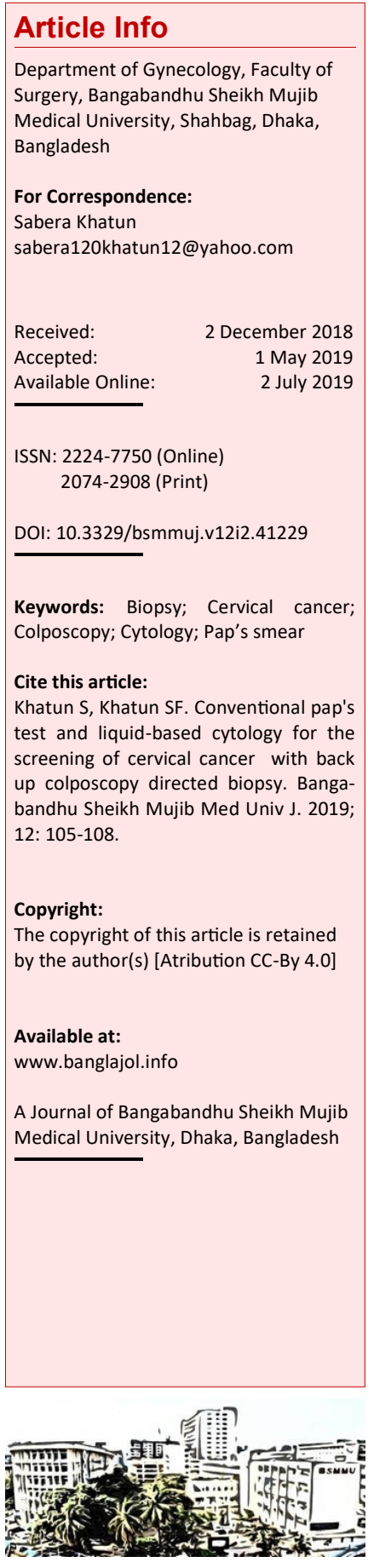

\section{Abstract}

The aim of this study was to screen the suspected cervical cancer patients $(n=100)$ by liquid-based cytology and conventional pap's smear followed by colposcopic biopsy from July 2016 to June 2017. In conventional pap's test, 73 cases were true negative whereas 25 cases were false negative. However, in liquid-based cytology, 68 cases were true negative and 23 cases were false negative. Finally when colposcopic examinations were done, 61 cases were true negative and 15 cases were false negative. The sensitivity of liquid-based cytology was $11.5 \%$ for cervical cancer screening which was more than the conventional pap's smear $(3.8 \%)$. In conclusion, liquid-based cytology should be more preferable method than the than conventional pap's smear for the diagnosis of precancerous lesion of the cervix.

\section{Introduction}

Cervical cancer is the second most common causes of death in gynecological cancer of women.1 For the last 60 years, the mainstay of cervical cancer screening is Papanicolaou test (pap test). It involves the examination of exfoliating cells from the transformation zone and detects cancerous or precancerous lesion. The test can be performed by traditional method or liquid-based cytology. In liquidbased cytology, collected cells are released into a vial of liquid preservative that is then used for microscopic evaluation of the cells. Traditional pap test involves direct transfer of the cervical cells to a microscope slide for evaluation. When abnormal cells are detected on the pap test, colposcopy is indicated. 2

The traditional pap's smear has a significant false negative rate of 15 to $40 \%$ where absolute sensitivity for CIN (cervical intraepithelial neoplasia) II-III is $50-89 \% .4-6$ The main factors for false negative rate are: specimen collection, smear formation, false error, deficiency of consistent sufficient number of cytotechnician.

There are two limitations of pap's smear which are false negative result and cost of the test.

Anyway, it is called primary gold standard screening test for cervical cancer due to higher specificity $(98.6 \%) . ?$

Liquid-based cytology has been associated with the reduction of unsatisfactory rate. $\frac{8}{\text { It }}$ has been suggested that the sensitivity of liquid-based cytology for the detection of CIN I-II is same as conventional cytology but its sensitivity for detection of CIN II-III is lower. Comparative performance of liquid-based cytology has suggested that sensitivity for detection of CIN II-III is similar to that of conventional cytology but specificity is lower.9 Another study showed that liquid-based cytology does perform better than conventional cytology in term of positive predictive value for detection of CIN -II or CINIII.10 Liquid-based cytology is found to be cost effective $\underline{11}$ and this test is important for detection of HPV-DNA testing. It is known that screening test has a higher sensitivity but conventional pap's test has long been known for its low sensitivity because of inadequate sample collection and interpretation difficulties.12 Liquid-based cytology has been well documented for its higher sensitivity. $\frac{13-15}{}$

\section{Materials and Methods}

This cross-sectional study was done at the department from July 2016 to June 2017. A total of 100 cases of women of reproductive age between 20-50 years with normal cervix were included in this study. Purposive sampling method was used to select the participants to collect data and information. A self-administered structured questionnaire was used to collect data. The purpose of the study was explained to all respondents who fulfilled the enrollment criteria.

\section{Statistical analysis}

The pre-designed data sheet was scrutinized to 
check the quality of the raw data. After crosschecking, coding was developed for each and every question. The variable was defined for a single observation with the value and value description was done according to the data type. After editing and coding, the coded data were analyzed by using SPSS 20.0 version.

\section{Results}

Results were compiled and manually analyzed. Total number of patients were 100. Among them $44 \%$ of patients were in the age range of 30-39 years. $28 \%$ were between $40-49$ years, $12 \%$ were less than 30 years and $16 \%$ of patients were more than 49 years.

Regarding the report of cervical cancer screening tests, conventional pap's test, liquid based cytology, colposcopic guided biopsy were done from 100 patients (Table I). The results of the conventional cytology was negative for CIN (98\%) and ASCUS (atypical squamous cell of undetermined significance) (2\%). In liquid-based cytology, negative for CIN was $91 \%$ and positive for CIN was $9 \%$. In colposcopic biopsy, CIN positive cases were 24 . In conventional pap's test, it was observed true positive 1 case, false positive 1 case, false negative 25 cases and true negative 73 cases. In liquid based cytology, true positive 3 cases, false positive 6 cases, false

\begin{tabular}{|lrrr|}
\hline \multicolumn{2}{|c|}{ Table I } & & \\
\hline & \multicolumn{3}{c|}{ Comparison of different test findings } \\
& & \multicolumn{2}{c|}{} \\
\cline { 3 - 4 } & & True & False \\
\hline Colposcopy & Positive & 11 & 13 \\
Conventional pap's test & Negative & 61 & 15 \\
& Positive & 1 & 1 \\
Liquid-based cytology & Negative & 73 & 25 \\
& Positive & 3 & 6 \\
& Negative & 68 & 23 \\
\hline
\end{tabular}

Table II

Sensitivity, specificity, accuracy, positive and negative predictive values for identification of cervical cancer

\begin{tabular}{|lccc|}
\hline Validity test & Colposcopy & $\begin{array}{c}\text { Conventional } \\
\text { pap's test }\end{array}$ & $\begin{array}{c}\text { Liquid-based } \\
\text { cytology }\end{array}$ \\
\hline Sensitivity & 42.3 & 3.8 & 11.5 \\
Specificity & 82.4 & 98.6 & 91.9 \\
Accuracy & 72.0 & 74.0 & 71.0 \\
Positive predictive value & 45.8 & 50.0 & 33.3 \\
Negative predictive value & 80.3 & 74.5 & 74.7 \\
\hline
\end{tabular}

negative 23 cases and true negative 68 cases were observed. In colposcopic evaluation it was observed, true positive 11 cases, false positive 13 cases, false negative 15 cases and true negative 61 cases.

In this study, the sensitivity of liquid-based cytology was $11.5 \%$ for cervical cancer screening which was more than conventional pap's smear $(3.8 \%)$ (Table II).

\section{Discussion}

This study showed positive for CIN $9 \%$ by liquidbased cytology which was more than conventional pap's test $(2 \%)$. On the other hand, CIN was positive in 24 cases by colposcopic biopsy in 100 patients. In this study, the sensitivity of liquidbased cytology was $11.5 \%$ for cervical cancer screening which was more than conventional pap's smear (3.8\%).

Liquid-based cytology increases the detection rate of low grade squamous intraepithelial lesion and high grade squamous intraepithelial lesion by 47 and $116 \%$ respectively compared with conventional pap's test which is correlated with this study. . $\mathrm{A}$ study reported similar results that liquid-based cytology test increases the detection rate of atypical squamous cell of undetermined significance, low grade squamous intraepithelial lesion and high grade squamous intraepithelial lesion cytology by $75.7,107.3$ and $64.5 \%$ respectively. 17 Another study showed high grade squamous intraepithelial lesion was more found in liquid-based cytology than conventional pap's smear. $\underline{18}$ Abnormal cytology was more by colposcopy and biopsy than other two screening procedure. So, the compliance of colposcopic procedure was higher compare to conventional pap's smear and liquid-based cytology. 19 The detection of intraepithelial lesion and cervical screening was advanced by using liquid-based cytology which was reported in another study. $\underline{20}$ In Japan, one study showed that the rate of high diagnosis of cervical cancer was more by liquidbased cytology.21-24. Liquid-based cytology proved to be a superior screening test to detect epithelial cell abnormality due to its higher sensitivity and positive predictive value which was reported by Vassilkos et al. (2000). .55 A study showed that the sensitivity was significantly greater in liquid-based cytology compared to the conventional cytology (96 vs $92 \%$ ) which is consistent with this study. 26 Another study also showed that in liquid-based cytology as a screening procedure of cervical cancer, sensitivity is greater $(81.4 \%)$ than conventional paps test. $\underline{27}$

The reasons for better findings of pre-invasive lesion of cervix by liquid-based cytology are: a) collection of sample is simple and technically easy and non-doctor can easily collect the sample, b) the 
smear made from sediment which contains undamaged healthy cell, c) smear is not contaminated by the necrosed cell, debris, blood or mucus. So, the detection of abnormal cells became easier, d) autosomal cytological examination give low false results.

\section{Conclusion}

Liquid-based cytology is better than the conventional pap's test as a screening procedure of cervical cancer which can be confirmed by colposcopic guided biopsy.

\section{Conflict of interest}

There is no conflict of interest with any person or group or agency about this work.

\section{Acknowledgement}

We are grateful to the Pro-Vice Chancellor (Research and Development) of Bangabandhu Sheikh Mujib Medical University for granting the financial support to run this project.

\section{Ethical Issue}

The ethical approval of the study was taken from the Institutional Review Board of Bangabandhu Sheikh Mujib Medical University.

\section{References}

1. Cervical cancer, human papillomavirus (HPV), and HPV vaccines: Key points for policy-makers and health professionals. World Health Organization, 2008.

2. American college of obstetricians and gynecologists. Cervical cancer screening and prevention. Practice Bulletin No. 157. Obstet Gynecol. 2016; 127: e1-20.

3. Howlader N, Noone AM, Krapcho M, Garshell J, Miller D, et al. SEER cancer statistics review, 19752012. National Cancer Institute. April 23, 2015. Available at http://seer.cancer.gov/ csr/1975_2012/.

4. U.S Preventive Services Task Force. Screening for cervical cancer. Ann intern Med. 1990; 113: 214-26.

5. Willkinson EJ. Pap smears and screening for cervical neoplasia. Clin Obstet Gynecol. 1990; 33: 817-25.

6. Fahey MT, Irwig L, Macaskill P. Meta-analysis of Pap-test accuracy. Am J Epidemiol. 1995; 141: 680-
89.

7. Begum SA, Rashid MH, Nessa A, Aziz MA, Zakaria SM, Roy JS. Comparative study between Pap smear and visual inspection using acetic acid as a method of cervical cancer screening. Comparative study. Mymensingh Med J. 2012; 21: 145-50.

8. Cervical Screening Programme NHS Cervical Screening Programme Annual Review 2012. 2012.

9. Arbyn M, Bergeron C, Klinkhamer P, MartinHirsch P, Siebers AG, Bulten J. Liquid compared with conventional cervical cytology: A systematic review and meta-analysis. Obstet Gynecol. 2008; 111: 167-77.

10. Siebers AG, Klinkhamer PJ, Grefte JM, Massuger LF, Vedder JE, Beijers-Broos A, Bulten J, Arbyn M. Comparison of liquid-based cytology with conventional cytology of cervical cancer precursors: A randomized controlled trail. JAMA. 2009; 302: 1757-64.

11. Canfell K. Models of cervical screening in the area of human papillomavirus vaccination. Sex Health. 2010; 7: 395-67.

12. Baandrup U, Bishop JW, Bonfiglio TA, Branca M, Hutchinson ML, Laverty CR, Ahmad J, Illescas LT, Obwegeser JH, Patnick J, Pogacnik A, Rosenthal DL, Suprun HZ, Verhest A, Richart RM. Sampling, sampling errors and specimen preparation. Acta Cytol. 2000; 44: 944-48.

13. Bastian L, Datta S, Hasselblad V. Evidence report: evaluation of cervical cytology. AHCPR. 1999; 2.

14. Weintraub J, Morabia A. Efficacy of a liquid-based thin layer method for cervical cancer screening in a population with a low incidence of cervical cancer. Diagn Cytopathol 2000; 22: 52-59.

15. Malle D, Pateinakis P, Chakka E, Destouni C. Experience with a thin-layer, liquid-based cervical cytologic screening method. Acta Cytol. 2003; 47: 129-34.

16. Marino JF, Fremont-Smith M. Direct-to-vial experience with AutoCyte PREP in a small New England regional cytology practice. J Reprod Med. 2001; 46: 353-58.

17. Fremont-Smith $\mathrm{M}^{1}$, Marino J, Griffin B, Spencer L, Bolick D. Comparison of the SurePath liquidbased Papanicolaou smear with the conventional Papanicolaou smear in a multisite direct-to-vial study. Cancer. 2004; 102: 269-79.

18. Mills SE, Carter D, Gresson JK, Reuter VE, Stoler MH. Sternberg's diagnostic surgical pathology. 4th ed. Philadelphia, Lippincott Williams and Wilkins, 2004, pp 2377-78.

19. Jhala D, Eltoum I. Barriers of adoption of recent technology in cervical screening. Cyto J. 2007; 4: 16.

20. Syrjänen K, Derchain S, Roteli-Martins C, LongattoFilho A, Hammes LS, Sarian L. Latin American Screening Study Group. Value of conventional pap 
smear, liquid-based cytology, visual inspection and human papillomavirus testing as optional screening tools among Latin American women $<35$ and $>$ or $=35$ years of age: Experience from the Latin American Screening Study. Acta Cytol. 2008; 52: 641-53.

21. Apgar BS, Brotzman GL, Spitzer M. Colposcopy: Principles and practice. $2^{\text {nd }}$ ed. Philadelphia, Saunders Company, 2002, p 209.

22. Schledermann D, Ejersbo D, Hoelund B. Significance of atypia in conventional Papanicolaou smears and liquid-based cytology: A follow-up study. Cytopathology 2004; 15: 148-53.

23. Karimi Zarchi M, Binesh F, Kazemi Z, Teimoori S, Soltani HR, Chiti Z. Value of colposcopy in the early diagnosis of cervical cancer in abnormal Pap smears in patients referred to the GgynecologyOncology clinic at Shahid Sadoughi Hospital, Yazd. Asian Pac J Cancer Prev. 2011; 12: 3439-41.
24. Akamatsua S, Kodama S, Himeji Y, Ikuta N, Shimagaki N. Comparison of liquid-based cytology with conventional cytology in cervical cancer screening. Acta Cytol. 2012; 56: 370-74.

25. Vassilakos P, Schwartz D, de MF, Yousfi L, Broquet G, Mathez-Loic F, Campana A, Major A. Biopsybased comparison of liquid-based, thin-layer preparations to conventional pap smears. J Reprod Med 2000; 45: 11-6.

26. Beerman H, van Dorst EB, Kuenen-Boumeester V, Hogendoorn PC. Superior performance of liquid -based versus conventional cytology in a population-based cervical cancer screening program. Gynecol Oncol. 2009; 112: 572-6.

27. Tanabodee J, Thepsuwan K, Karalak A, Laoaree O, Krachang A, Manmatt K, Anontwatanawong N. Comparison of efficacy in abnormal cervical cell detection between liquid-based cytology and conventional cytology. Asian Pac J Cancer Prev. 2015; 16: 7381-84. 